\title{
Dissolved organic carbon driven by rainfall events from a semi-arid catchment during concentrated rainfall season in the Loess Plateau, China
}

\author{
Linhua Wang ${ }^{1}$, Haw Yen $^{2}$, Xinhui $\mathrm{E}^{1,3}$, Liding Chen ${ }^{1,3}$, and Yafeng Wang ${ }^{1,3,4}$ \\ ${ }^{1}$ State Key Laboratory of Urban and Regional Ecology, Research Center for Eco-Environmental Science, \\ Chinese Academy of Sciences, Beijing 100085, China \\ ${ }^{2}$ Blackland Research and Extension Center, Texas A\&M AgriLife Research, Texas A\&M University, Texas, 76502, USA \\ ${ }^{3}$ College of Resources and Environment, University of Chinese Academy of Sciences, Beijing 100049, China \\ ${ }^{4}$ Institute of Tibetan Plateau Research, Chinese Academy of Sciences, Beijing 100101, China
}

Correspondence: Yafeng Wang (yfwang@rcees.ac.cn)

Received: 6 January 2019 - Discussion started: 30 January 2019

Revised: 25 June 2019 - Accepted: 4 July 2019 - Published: 25 July 2019

\begin{abstract}
Dissolved organic carbon (DOC) transported by runoff has been identified as an important role in the global carbon cycle. Despite there being many studies on DOC concentration and flux, little information is available for the semi-arid catchments of the Loess Plateau region (LPR). The primary goal of this study was to quantify DOC exported and driven by a sequence of rainfall events during the concentrated rainfall season. In addition, factors that affect DOC export from a small headwater catchment will be investigated accordingly. Runoff discharge and DOC concentration were monitored at the outlet of the Yangjuangou catchment in Yanan, Shaanxi Province, China. The results showed that DOC concentration was highly variable, with event-based DOC concentrations ranging from 5.14 to $13.14 \mathrm{mg} \mathrm{L}^{-1}$. Hysteresis analysis showed a nonlinear relationship between DOC concentration and flow rate in the hydrological process. The monthly DOC flux loading from the catchment was varied from 94.73 to $110.17 \mathrm{~kg} \mathrm{~km}^{-2}$, while the event-based DOC flux ranged from 0.18 to $2.84 \mathrm{~kg} \mathrm{~km}^{-2}$ in the period of June to September. Variations of eventdriven DOC concentration contributed slightly to a difference in DOC flux, whereas intra-events of rainfall amount and runoff discharge led to evident differences in DOC export. In conclusion, our case results highlighted the advantages of high-frequency monitoring for DOC export and indicated that event-driven DOC export is largely influenced by the interaction of catchment hydrology and antecedent condition within a catchment. Engineers and scientists can take
\end{abstract}

advantage of the derived results to better develop advanced field monitoring work. In addition, more studies are needed to investigate the magnitude of terrestrial DOC export in response to projected climate change at larger spatio-temporal scales, which may have implications for the carbon balance and carbon cycle model from an ecologically restored catchment in the LPR.

\section{Introduction}

Dissolved organic carbon (DOC), often defined as the solute filtered through $<0.45 \mu \mathrm{m}$ pore size, is regarded as one of the active constituents and provides a biologically available carbon source for organisms (Raymond and Saiers, 2010). The estimated DOC flux of terrestrial organic carbon through major worldwide rivers to oceans is from 0.45 to $0.78 \mathrm{Pg} \mathrm{C} \mathrm{yr}^{-1}$ (Drake et al., 2018; Hedge et al., 1997; Ran et al., 2018). The substantial magnitude of flux suggests that the DOC export on a global scale acts as one of the crucial processes of linking between terrestrial and aquatic ecosystem (Battin et al., 2008; Raymond et al., 2013; Raymond and Saiers, 2010). For instance, high DOC concentrations can lead to water pollution and eutrophication and thus have dramatic consequences for aquatic ecosystem services (Evans et al., 2005; Hu et al., 2016). In addition to ecological impacts, DOC in runoff also plays an important role in social well-being. High DOC concentrations will aggravate the complexation and adsorption 
of pesticides and heavy metals in hydrological processes. Therefore, the quality of domestic water could be damaged and it might potentially lead to adverse impacts on human health, such as increased risk of cancer, diabetes, or other diseases (Bennett et al., 2009; Ritson et al., 2014). Therefore, it is urgent to improve the associated knowledge of DOC export variability and develop a thorough understanding of DOC export from catchments.

DOC transport from catchments has attracted great attention in the last two decades due to global concerns about potential influences on the global carbon cycle and climate change (Laudon et al., 2004; Raymond et al., 2013). The transport of terrestrial DOC to runoff is strongly influenced by hydrological processes, the soil carbon cycle and climatological factors. Hydrological processes driven by rainfall events play an important role in controlling terrestrial DOC from the soil carbon pool to runoff. Previous studies have shown that the release of DOC concentrations ranged from 0.5 to $50 \mathrm{mg} \mathrm{L}^{-1}$ for global catchments (Mulholland, 2003). For instance, Clark et al. (2007) found that DOC concentration varied from 5 to $35 \mathrm{mg} \mathrm{L}^{-1}$ with high variability in rainfall events from a peatland catchment, and a study by Blaen et al. (2017) showed that the DOC concentration ranged from 5.4 to $18.9 \mathrm{mg} \mathrm{L}^{-1}$. Similar results were reported by Ran et al. (2018), who found that DOC concentration ranged from 1.4 to $9.5 \mathrm{mg} \mathrm{L}^{-1}$ in the Wuding River in the Loess Plateau region (LPR). Such studies highlight the importance of hydrological processes on DOC transport (Billett et al., 2006; Dawson et al., 2002; Inamdar et al., 2006). Different rainfall events may alter hydrological connectivity or the flow path, which in turn leads to a varied hydrological condition and DOC sources contributing to runoff. Moreover, the intensity and frequency of rainfall events not only influence the hydrology and DOC loading processes, but also change the soil moisture conditions (Yang et al., 2018). The latter point may be particularly important in the soil biogeochemical cycle. For example, DOC concentration may increase due to accumulated soil organic carbon after a dry period (Jager et al., 2009). In addition, variations in the magnitude and frequency of precipitation are one of the manifestations of climate change, and thus changes in hydrological processes induced by climate change also impact on the transport of terrestrial DOC. Therefore, understanding the dynamic and magnitude of DOC export from catchments is an important component in the prediction of DOC flux under the circumstances of future climate change.

The LPR, which has an area of $6.4 \times 10^{5} \mathrm{~km}^{2}$, is situated in the middle reaches of the Yellow River, China, and approximately $90 \%$ of the river loading sediment is derived from this region (Tang, 2004). With regards to this fragile environment, the Chinese government has launched some ecological restoration projects since the beginning of this century, such as the "Grain-for-Green" and "Natural Forest Protection Project". With the implementation of these projects, large areas of steep-sloping (higher than $20^{\circ}$ ) agricultural land was converted to forest, shrub, or grassland, and engineering measures were also applied to control erosion ( $\mathrm{Fu}$ et al., 2017). For instance, check dams can retain sediment and also offer flat and fertile land behind the dam (Wang et al., 2011a). These measures have caused the Loess Plateau to experience a substantial change in land use, vegetation cover, soil properties, and catchment hydrology (Chen et al., 2007; Wang et al., 2011b; Wei et al., 2014). Consequently, the hydrological and carbon biogeochemical processes, which operate and interact with each other, were dramatically altered (Liang et al., 2015a, b). These changes in hydrology and soil carbon cycle induced by land use and vegetation change may be particularly important in the dynamics of DOC concentration and flux in an ecologically restored catchment. Moreover, DOC transport from a catchment is sparsely measured due to the DOC concentration in hydrological processes not being treated as a general parameter in the monitoring networks of LPR. Therefore, less information is available on DOC export driven by rainfall events, of which DOC flux is an important component in the overall carbon balance for ecologically restored catchments.

Therefore, the primary goal of this study is to investigate how variations of DOC concentration and flux respond to a sequence of rainfall events from a restored catchment during a concentrated rainfall season in the LPR. Specifically, the two objectives of this study were (1) to examine the dynamic changes in DOC concentration and flux and assess the difference in DOC export driven by various rainfall events, and (2) to evaluate how rainfall, runoff, and antecedent factors affect DOC export from a catchment. To do so, we used a high-frequency method to capture the temporal changes in DOC export and hydrological processes driven by rainfall event within an ecologically restored watershed in the LPR. These results will provide evidence of DOC export response to rainfall events, especially extreme events, which may be important for evaluating the carbon balance and modelling DOC export through runoff at ecologically restored catchments in the LPR.

\section{Materials and methods}

\subsection{Site description}

As shown in Fig. 1, this study was conducted in the Yangjuangou catchment $\left(36^{\circ} 42^{\prime} \mathrm{N}, 109^{\circ} 31^{\prime} \mathrm{E}\right)$, which is an Ecological Restoration and Soil and Water Conservation Monitoring Station situated in Yan'an, Shaanxi Province, China. The catchment located in the secondary tributary of the Yan River Watershed and covers an area of $2.02 \mathrm{~km}^{2}$, ranging in elevation from 1050 to $1295 \mathrm{~m}$ above the mean sea level. The topography is characterized by a typical loess hilly and gully topography with a gully density of $2.74 \mathrm{~km} \mathrm{~km}^{-2}$ (Wang et al., 2011b). This catchment has a semi-arid continental monsoonal climate with an average annual tempera- 
ture of $9.6^{\circ}$ and average annual precipitation of $535 \mathrm{~mm}$ during the period from 1951 to 2012 ( $\mathrm{Li}$ and Wang, 2015). Furthermore, the precipitation is unevenly distributed throughout the year and $60 \%-70 \%$ of annual precipitation is concentrated from June to September (Shi and Shao, 2000). The soil is classified as a typical loess with a fine silt texture and is weakly resistant to detachment by raindrops or runoff. Two check dams were built in the main gully in the 1960s and are currently filled with sediment and used for agricultural purposes. Land use is dominated by forest with a mix of shrub, grassland, and arable land. The proportion of sloping cropland has decreased remarkably from $16.9 \%$ in 1998 to $0.1 \%$ in 2006 . The forest cover increased from $15.2 \%$ in 1998 to $37.4 \%$ in 2006 since the "Grain-forGreen" and engineering measures were implemented (Wang et al., 2011b). The major forest species are Robinia pseudoacacia, Salix spp. and Populus spp. The areas with Artemisa argyi, Stipa bungeana Trin., Bothriochloa ischaemum, Lespedeza davurica Schindl., and Artemisia sacrorum are classified as grassland. The major fruit trees are Prunus armeniaca L., Malus pumila Mill., and Juglans regia L. The major crops are Setaria italica, Zea may L. Glycine max (L) Merr. Panicum miliaceum L. and Solanum tuberosum (Fu et al., 2014). Therefore, the Yangjuangou catchment was chosen as a study site which represents an ecologically restored catchment.

\subsection{Field monitoring and sampling}

To measure the temporal dynamics of DOC, a monitoring station was deployed at the outlet of the Yangjuangou catchment to sample runoff water and monitor discharge. The station was equipped with an ISCO 6712 (Lincoln, NE, USA) peristaltic pump for collecting water samples during a runoff process induced by rainfall events. Unlike the common monthly or weekly sampling frequency at field observatory stations, the high-frequency monitoring was carried out in a hydrological process driven by a rainfall event in this study. Researchers resided in the field observatory station and treated the samples immediately after a rainfall event to ensure that the DOC in the sampled water did not microbially degrade (Kieber et al., 2002; Willey et al., 2000). The time-consuming and laborious field work is also one of the reasons for the measurement scarcity of DOC export in the existing ecosystem monitoring networks. Thus, the ISCO was set to acquire samples every $10 \mathrm{~min}$ from the first 12 runoff samples and another 12 were sampled every $30 \mathrm{~min}$. The equipment was programmed to monitor runoff discharge by capturing the flow rate $\left(\mathrm{L} \mathrm{s}^{-1}\right)$ and interval time (min). The auto-sampler collects a runoff sample with a volume of $200 \mathrm{~mL}$. The auto-sampler ceased sampling work after 24 samples were collected. Then, the experimenter poured the runoff water into high-density polyethylene bottles that were prewashed with ultra-pure water. The auto-sampler continued to monitor the hydrological process and sample runoff for the next rainfall event. There were 278 samples collected for 22 hydrological processes induced by the rainfall event over the monitoring period of June to September 2016. In addition, the aim of hydrological and meteorological factor monitoring was to characterize the temporal changes in catchment conditions. A meteorological station was installed in the centre of the catchment, which was away from high trees. It was used to continuously monitor the rainfall characteristics, air temperature, and soil moisture throughout the study period. Rainfall amount $\left(R_{\mathrm{a}}, \mathrm{mm}\right)$ and air temperature were measured every $30 \mathrm{~min}$. The volumetric soil moisture content at $20 \mathrm{~cm}$ depth of the forest land was measured every $30 \mathrm{~min}$, which accounts for a large proportion of land use. Because these factors drive the hydrological and carbon biogeochemical processes in the catchment, these monitoring works may offer another perspective for understanding the runoff and DOC export process within an individual or continuous temporal variation between rainfall events (Blaen et al., 2017).

\subsection{Laboratory analysis}

In the Yangjuangou field station, $200 \mathrm{~mL}$ of the collected runoff water sample was immediately filtered through a $0.45 \mu \mathrm{m}$ membrane into high-density polyethylene bottles and stored in a cooler $\left(4^{\circ} \mathrm{C}\right)$. Then, the samples were transported to the State Key Laboratory of Urban and Regional Ecology in Beijing for analysis. DOC was recognized as the difference between total dissolved carbon (TDC) and dissolved inorganic carbon (DIC) for each sample $(\mathrm{DOC}=\mathrm{TDC}-\mathrm{DIC})$. TDC and DIC were determined by Vario Select (Elementar, Germany), which included a hightemperature combustion furnace, a self-contained acidification module and a highly sensitive $\mathrm{CO}_{2}$ detector. TDC was automatically measured by the combustion of a sample, whereas DIC was measured after acidification by a $1 \%$ $\mathrm{H}_{3} \mathrm{PO}_{4}$ solution (phosphoric acid). Then, validation was conducted by analysing various concentrations of a standard solution to achieve accurate results. In order to control quality, each sample was determined through analysis of two replicates and the coefficient of variation of tested results was less than $10 \%$.

\subsection{Data analysis}

\subsubsection{Event-driven DOC concentration and flux calculation}

In the present study, the flow-weighted mean concentration $\left(C_{\mathrm{f}}\right)$ was used to determine the average DOC concentration in a rainfall event. $C_{\mathrm{f}}$ was calculated by dividing the total DOC load by the total discharge in an event time. The equations of the flow-weighted mean concentration and flux are defined 
as the following:

$$
\begin{aligned}
C_{\mathrm{f}} & =\frac{\sum_{i=1}^{n} C_{i} \times Q_{i}}{\sum_{i=1}^{n} Q_{i}}, \\
\text { flux } & =\frac{10^{-6} \times C_{f} \times \sum_{i=1}^{n} Q_{i}}{S},
\end{aligned}
$$

where $Q_{i}(\mathrm{~L})$ is the discharge amount corresponding to sample $i$, which is calculated by flow rate and interval time; $C_{i}$ $\left(\mathrm{mg} \mathrm{L}^{-1}\right)$ is the DOC concentration in a runoff sample $i$; and $n$ is the total number of collected sample in a runoff event. Flux $\left(\mathrm{kg} \mathrm{km}^{-2}\right)$ is the quantity of DOC driven by a rainfall event in the study region, and $s$ is the catchment area $\left(\mathrm{km}^{2}\right)$.

\subsubsection{Variables related to event-driven DOC transport}

To better understand DOC concentrations and fluxes from a catchment, specific hydrological and meteorological variables were selected. For instance, rainfall and soil moisture content may be related to hydrological connectivity in a runoff event, while soil moisture and temperature conditions impact on soil organic carbon content through biological processes (Blaen et al., 2017; Cooper et al., 2007; Soulsby et al., 2003). These variables are $Q$ (total discharge volume of rainfall); $R_{\mathrm{a}}$ (total rainfall amount in a rainfall event); $R 1, R 7$ and $R 14$ (total rainfall amount in the 1,7 and $14 \mathrm{~d}$ before the rainfall event, respectively); SMC-7 and SMC-14 (soil moisture content in the 7 and $14 \mathrm{~d}$ before the rainfall event); $T_{\text {air }}-7$ and $T_{\text {air-14 }}$ (mean air temperature in the 7 and $14 \mathrm{~d}$ before the rainfall event); and REI (interval days between two rainfall events).

\subsubsection{Statistical analysis}

To analyse potential relationships among DOC concentration, flux, and selected variables, Pearson's test was performed using SPSS (Statistics Package for Social Science, Version 22). The corresponding figures were developed using Sigma Plot 10.0 (Systat, 2008).

\section{Results}

\subsection{Rainfall and discharge in the study catchment}

Rainfall is the main driving force of hydrological processes in a catchment. Event-based rainfall amount varied from $62.6 \mathrm{~mm}$ (18 July) to $0.60 \mathrm{~mm}$ (17 August) from June to September 2016 (Table 1). Over this period, the total rainfall amount was $372.1 \mathrm{~mm}$, with approximately $70 \%$ of the annual rainfall amount. All the rainfall events in between June to September were grouped into four grades: $<5 \mathrm{~mm}$ (light rainfall), 5-10 $\mathrm{mm}$ (moderate rainfall), 10$20 \mathrm{~mm}$ (heavy rainfall), and $>20 \mathrm{~mm}$ (violent rainfall) according to rainfall amount classification (Yang et al., 2018). Figure $3 \mathrm{a}$ showed that the total rainfall amounts were
41.1, 44.8, 99.6, and $186.6 \mathrm{~mm}$ for each grade, respectively. The occurrence frequencies of rainfall in each grade were $52.4 \%$ (<5 mm), $17.1 \%(5-10 \mathrm{~mm}), 16.7 \%$ (10-20 mm), and $14.3 \%$ (>20 mm) (Fig. 3b). These results indicate that the light and moderate rainfall occurs frequently with a lower total rainfall amount, whereas the majority of rainfall amount occurs with a lower chance of violent rainfall.

In general, flow discharge tended to follow the pattern of rainfall amount in the study catchment. The mean flow rate at the outlet of the catchment was $0.46 \mathrm{~L} \mathrm{~s}^{-1}$, but it was also more variable and ranged from 0 to $4.5 \mathrm{~L} \mathrm{~s}^{-1}$ during June to September 2016. In particular, there was no runoff in the catchment, due to the higher temperature, evapotranspiration and lower rainfall amount in early July. The higher flow rate is caused by continuous heavy rainfall. For instance, the cumulative rainfall amount was $91.8 \mathrm{~mm}$ and the mean flow rate was $4.05 \mathrm{~L} \mathrm{~s}^{-1}$ on 18-19 July (Table 1). Therefore, the flow rate increased rapidly within a short duration due to violent rainfall. In addition, Fig. 4a showed the relationship between the flow rate and rainfall amount during June to September. This indicated that the event-driven flow rate varied with rainfall amount and thus suggested that runoff discharges are highly sensitive to rainfall amounts higher than $20 \mathrm{~mm}$ in this area.

\subsection{DOC concentrations in runoff discharges}

\subsubsection{Event-based DOC concentrations during concentrated rainfall season}

In general, the monthly mean DOC concentration tended to decrease, from $11.52 \mathrm{mg} \mathrm{L}^{-1}$ in June to $6.81 \mathrm{mg} \mathrm{L}^{-1}$ in $\mathrm{Au}$ gust, and then slightly increased to $7.49 \mathrm{mg} \mathrm{L}^{-1}$ in September (Table 1). There were less variations in the mean DOC concentration among monitoring months. For the eventdriven DOC concentration, the flow-weighted mean DOC concentration $\left(C_{\mathrm{f}}\right)$ ranged from 5.14 to $13.14 \mathrm{mg} \mathrm{L}^{-1}$ for all sampled rainfall events during June to September (Table 1). The relationship between flow rate and $C_{\mathrm{f}}$ for sampled rainfall events is shown in Fig. $4 \mathrm{~b}$. The $C_{\mathrm{f}}$ exhibited a poor relationship with flow rate, and the $C_{\mathrm{f}}$ was more variable at low flow rates period compared to the high-flow-rate period, which was typically observed during consecutive rainfall events with high rainfall amounts. In addition, Table 2 showed the correlation between $C_{\mathrm{f}}$ and a set of factors in all sampled rainfall events during the study period. On the one hand, the $C_{\mathrm{f}}$ was positively correlated with rainfall amount $\left(R_{\mathrm{a}}\right)$ and $R 7$. On the other hand, the $C_{\mathrm{f}}$ was significantly extreme and negatively correlated with SMC-7 and SMC-14. These results showed that different rainfall and soil moisture conditions may affect DOC concentrations for a rainfall event. 


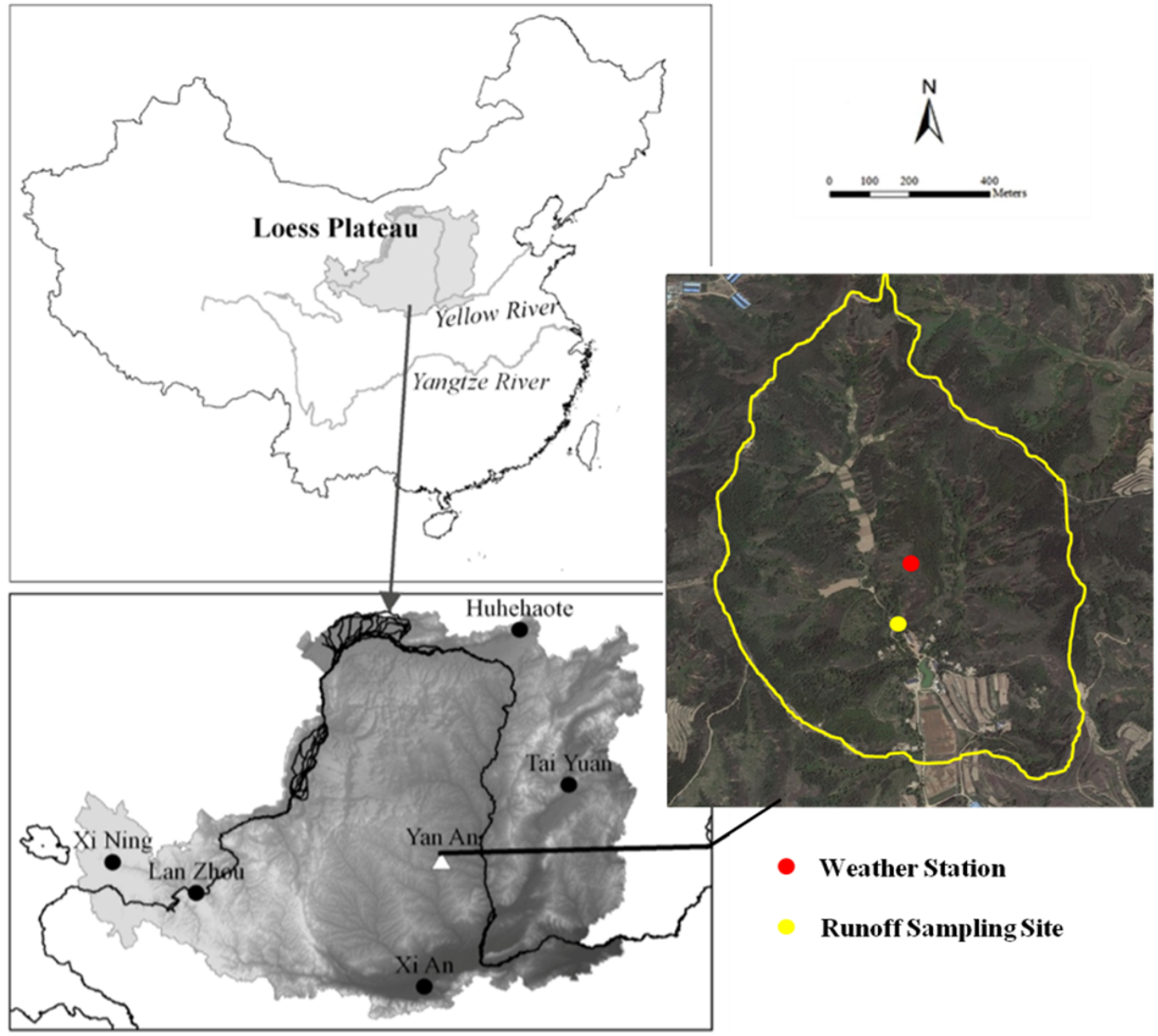

Figure 1. Geographic location of the Yangjuangou catchment in the Loess Plateau region, China; the red and yellow dots denote the weather station and runoff sampling site (source: Wang et al., 2017).

Table 1. Characteristics of rainfall amount $\left(R_{\mathrm{a}}\right)$, flow rate, DOC concentration $\left(C_{\mathrm{f}}\right)$ and flux for event-based samples collected during the concentrated rainfall season (June-September 2016).

\begin{tabular}{|c|c|c|c|c|c|c|c|c|c|}
\hline Date & $\begin{array}{r}R_{\mathrm{a}} \\
(\mathrm{mm})\end{array}$ & $\begin{array}{l}\text { Flow rate } \\
\left(\mathrm{L} \mathrm{s} \mathrm{s}^{-1}\right)\end{array}$ & $\begin{array}{r}C_{\mathrm{f}} \\
\left(\mathrm{mg} \mathrm{L}^{-1}\right)\end{array}$ & $\begin{array}{r}\text { Flux } \\
\left(\mathrm{kg} \mathrm{km}^{-2}\right)\end{array}$ & Date & $\begin{array}{r}R_{\mathrm{a}} \\
(\mathrm{mm})\end{array}$ & $\begin{array}{l}\text { Flow rate } \\
\left(\mathrm{L} \mathrm{s}^{-1}\right)\end{array}$ & $\begin{array}{r}C_{\mathrm{f}} \\
\left(\mathrm{mg} \mathrm{L}^{-1}\right)\end{array}$ & $\begin{array}{r}\text { Flux } \\
\left(\mathrm{kg} \mathrm{km}^{-2}\right)\end{array}$ \\
\hline 1 Jun & 1.0 & 0.56 & 10.87 & 0.52 & $1 \mathrm{Aug}$ & 0.8 & 0.54 & 5.14 & 0.24 \\
\hline 2 Jun & 7.0 & 0.59 & 9.97 & 0.51 & 2 Aug & 4.2 & 0.63 & 9.72 & 0.53 \\
\hline 3 Jun & 3.0 & 0.53 & 10.53 & 0.48 & 6 Aug & 0.8 & 0.47 & 7.95 & 0.32 \\
\hline 5 Jun & 3.2 & 0.53 & 11.59 & 0.53 & 12 Aug & 0.8 & 0.40 & 5.30 & 0.18 \\
\hline 7 Jun & 13.8 & 0.65 & 12.96 & 0.73 & 13 Aug & 1.2 & 0.35 & 5.93 & 0.18 \\
\hline Jun & 82.9 & 0.35 & 11.52 & 102.39 & 16 Aug & 18.8 & 0.96 & 6.46 & 0.54 \\
\hline $11 \mathrm{Jul}$ & 24.6 & 0.44 & 11.92 & 0.45 & 17 Aug & 0.6 & 0.55 & 9.69 & 0.46 \\
\hline 13 Jul. & 19.8 & 1.28 & 11.84 & 1.31 & 18 Aug & 1.2 & 0.57 & 7.44 & 0.37 \\
\hline $14 \mathrm{Jul}$ & 11.0 & 0.46 & 13.00 & 0.52 & Aug & 53.8 & 0.53 & 6.81 & 94.73 \\
\hline $18 \mathrm{Jul}$ & 62.6 & 1.46 & 11.64 & 1.47 & 9 Sep & 6.8 & 0.44 & 13.14 & 0.50 \\
\hline 19 Jul & 29.2 & 4.05 & 8.12 & 2.84 & $10 \mathrm{Sep}$ & 21.8 & 1.24 & 7.21 & 0.77 \\
\hline $31 \mathrm{Jul}$ & 2.2 & 0.54 & 6.70 & 0.31 & $17 \mathrm{Sep}$ & 6.2 & 0.48 & 9.10 & 0.38 \\
\hline Jul & 184.2 & 0.41 & 8.95 & 96.57 & Sep & 51.2 & 0.57 & 7.49 & 110.17 \\
\hline
\end{tabular}




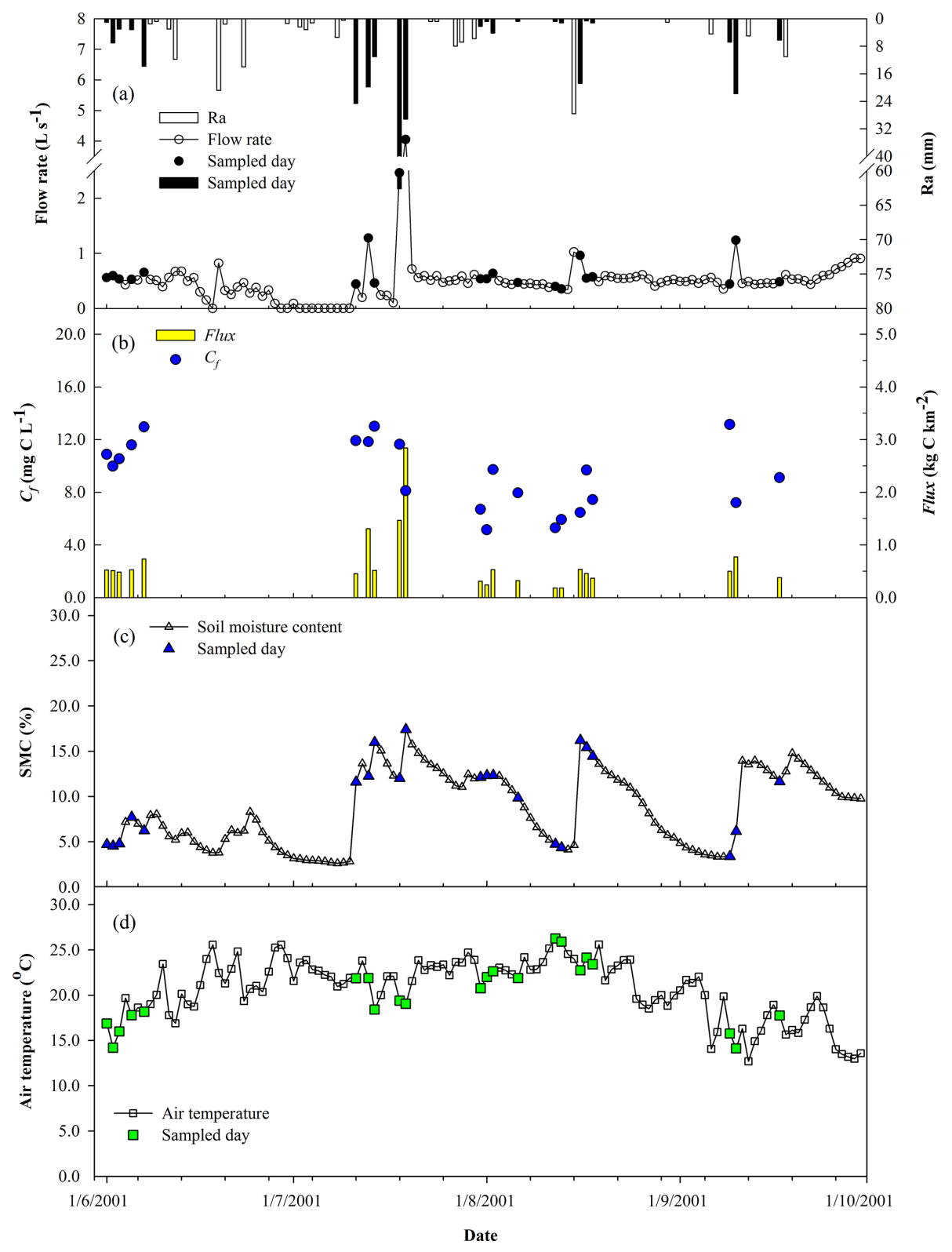

Figure 2. Temporal variations in $R_{\mathrm{a}}$ (rainfall amount) and flow rate (a), $C_{\mathrm{f}}$ (flow-weighted mean concentration) and flux (b), SMC (soil moisture content) (c), and air temperature (d) during the concentrated rainfall season (June-September 2016).

\subsubsection{Dynamic changes of DOC concentrations in a rainfall event}

Four rainfall events of total sampled events were chosen for detailed examination of the relationship between DOC concentration $\left(C_{i}\right)$ and flow rate in the hydrological process. These selected rainfall events represented $83 \%$ of the occurrence frequency of rainfall, and the high-frequency samples collected cover a complete hydrological process during the monitoring period. Figure 5 shows the dynamic changes in DOC concentration and flow rate via the hydrograph over an event-driven hydrological process. In general, $C_{i}$ varied between the runoff discharge process induced by different rainfall amounts. $C_{i}$ increased quickly in the increasing trend of the hydrograph and the maximum concentration occurred behind the peak of the hydrograph on 7 June (Fig. 5a) and 2 August (Fig. 5c), a period with less rainfall and of a long duration. $C_{i}$ then decreased from 1.35 to $0.41 \mathrm{mg} \mathrm{L}^{-1}$ during the decreasing trend on 2 August, while $C_{i}$ remained at relatively high values at $1.41-1.50 \mathrm{mg} \mathrm{L}^{-1}$ in the decreasing trend on 7 June. During rainfall events on 13 July (Fig. 5b) and 10 September (Fig. 5d), the discharge hydrograph exhibited a higher fluctuation due to the high rainfall amount and short rainfall duration. $C_{i}$ was kept relatively stable de- 

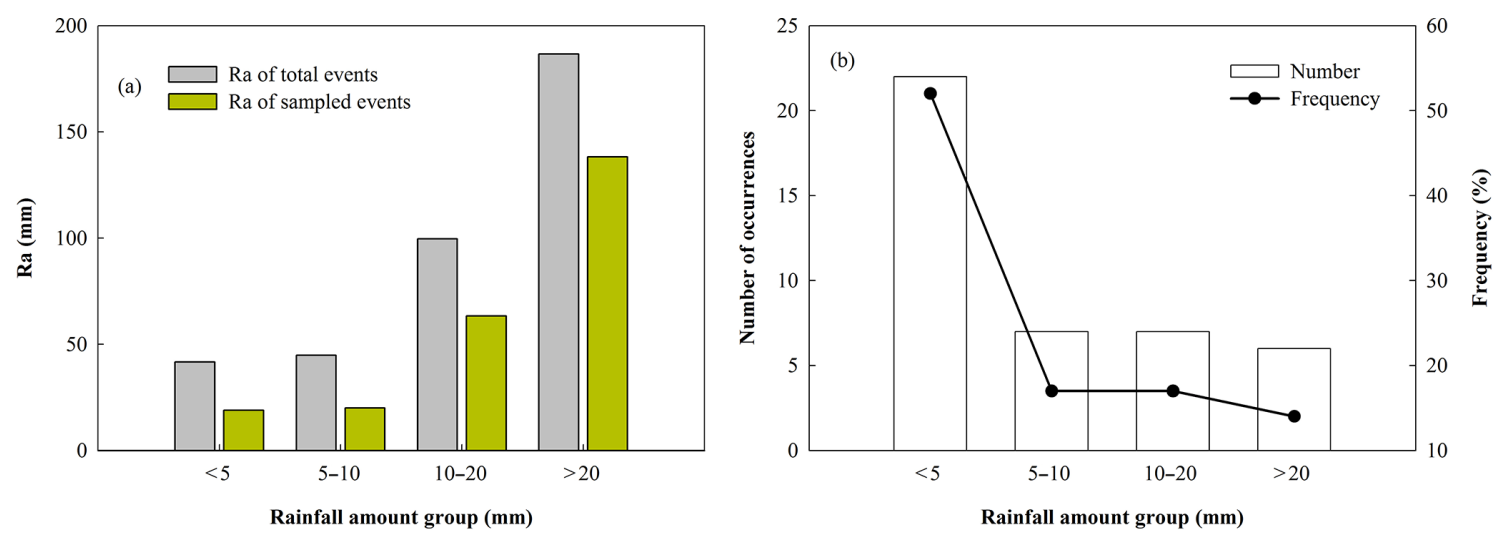

Figure 3. Statistical characteristics of rainfall events from June to September 2016: (a) characteristics of total and sampled rainfall amount, (b) characteristics of rainfall amount grades and its occurrence frequency.
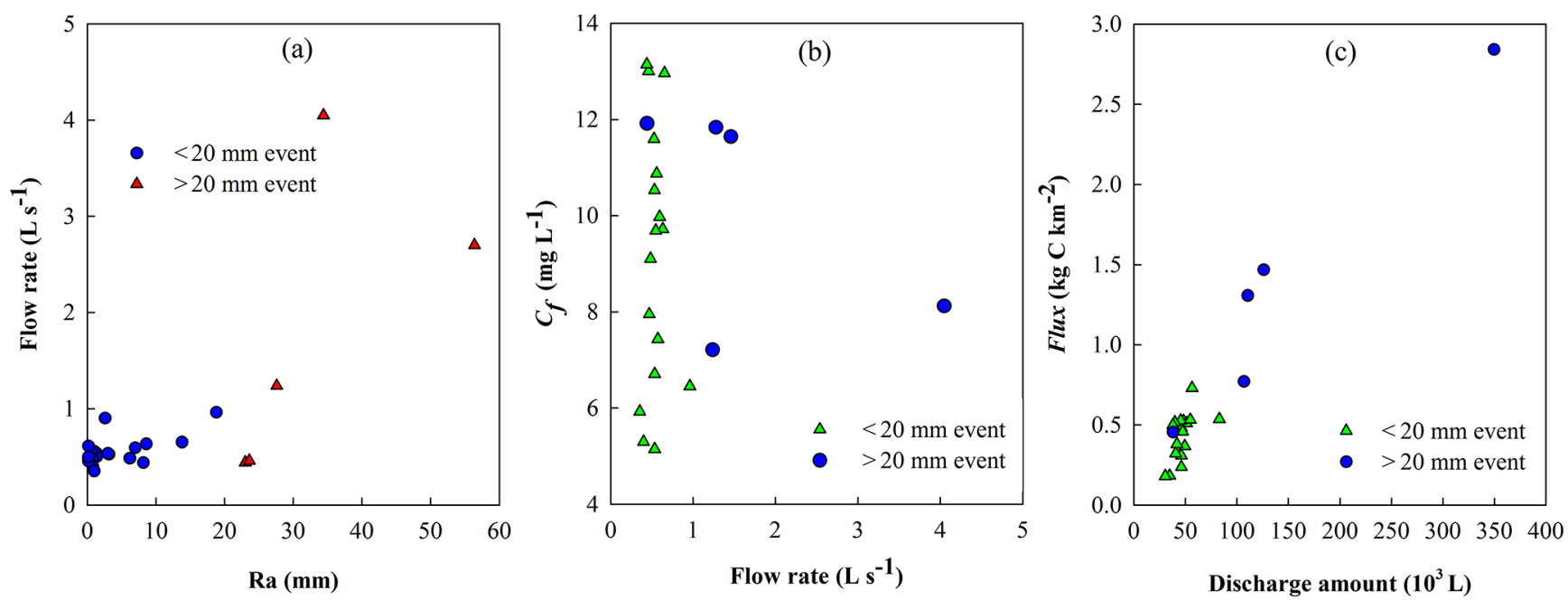

Figure 4. Relationships between $R_{\mathrm{a}}$ (rainfall amount) and flow rate (a), $C_{\mathrm{f}}$ (flow-weighted mean concentration) and flow rate (b), and flux and total discharge (c) for sampled rainfall events during the monitoring period (June-September 2016).

spite the fact that it increased from 1.05 to $1.30 \mathrm{mg} \mathrm{L}^{-1}$ during the upward trend on 13 July. However, $C_{i}$ sharply increased from 0.61 to $1.24 \mathrm{mg} \mathrm{L}^{-1}$ and the maximum $C_{i}$ was observed before the peak of the hydrograph. $C_{i}$ then declined and remained stable, ranging from 0.61 to $0.75 \mathrm{mg} \mathrm{L}^{-1}$ during the decreasing trend on 10 September. Overall, the dynamic changes in $C_{i}$ in the hydrograph show that the DOC export process varied with different rainfall and runoff conditions.

\subsection{Hysteresis of event-driven DOC concentrations}

The above results showed a nonlinear correlation between flow rate and DOC concentrations $\left(C_{i}\right)$ over a rainfall event. Therefore, a hysteresis analysis was used to examine the dynamic changes of the $C_{i}$ response to a hydrological process, which has been applied to investigate the temporal variation in solute concentration with flow rate (Blaen et al., 2017;
Lloyd et al., 2016a, b; Tunaley et al., 2017). Figure 7 shows that $C_{i}$ varied in the rising and falling hydrograph during four selected rainfall events. Three hysteresis patterns were observed, including clockwise (13 July and 10 September), anti-clockwise (7 June) and figure-of-eight (2 August). As shown in Fig. 6a, $C_{i}$ was higher during the decreasing trend than during the increasing trend of the hydrograph, thus resulting in an anti-clockwise pattern. A figure-of-eight pattern indicated that $C_{i}$ generally varied in pace with runoff discharge on 2 August 2016 (Fig. 6c). The difference in $C_{i}$ between rising and falling trends at a given flow rate was small, as supported by the results shown in Fig. 5c. On 13 July (Fig. 6b) and 10 September (Fig. 6d), $C_{i}$ exhibited a clockwise pattern, which implied that $C_{i}$ was higher in the rising trend than in the falling trend. The relationships between concentration and flow rate highlighted that the DOC export behaviour was different in a complete hydrological process driven by a single rainfall event. 
Table 2. Summary of correlation coefficients between $C_{\mathrm{f}}$, flux and a set of factors.

\begin{tabular}{lcrrrrrrrrrr}
\hline & Flux & $Q$ & $R_{\mathrm{a}}$ & $R 1$ & $R 7$ & $R 14$ & REI & $T_{\text {air }}-7$ & $T_{\text {air }}-14$ & SMC-7 & SMC-14 \\
\hline$C_{\mathrm{f}}$ & 0.30 & -0.01 & 0.30 & -0.01 & 0.23 & -0.05 & $-0.32^{*}$ & -0.25 & -0.24 & $-0.44^{* *}$ & $-0.65^{* *}$ \\
Flux & & $0.94^{* *}$ & $0.69^{* *}$ & $0.76^{* *}$ & $0.57^{* *}$ & 0.29 & -0.14 & -0.07 & -0.04 & 0.06 & -0.24 \\
$Q$ & & & $0.60^{* *}$ & $0.85^{* *}$ & $0.53^{* *}$ & $0.33^{*}$ & -0.07 & -0.02 & 0.01 & 0.19 & -0.03 \\
$R_{\mathrm{a}}$ & & & & $0.38^{*}$ & $0.39^{*}$ & 0.14 & -0.06 & 0.02 & 0.07 & -0.05 & -0.30 \\
$R 1$ & & & & & $0.58^{* *}$ & $0.42^{* *}$ & -0.27 & 0.11 & 0.10 & 0.12 & -0.01 \\
$R 7$ & & & & & & $0.69^{* *}$ & -0.28 & 0.24 & 0.23 & $0.40^{* *}$ & 0.02 \\
$R 14$ & & & & & & & -0.20 & 0.19 & 0.13 & $0.56^{* *}$ & $0.42^{* *}$ \\
REI & & & & & & & & -0.02 & 0.03 & 0.26 & 0.25 \\
$T_{\text {air }}$-7 & & & & & & & & & $0.96^{* *}$ & 0.09 & 0.20 \\
$T_{\text {air-14 }}$ & & & & & & & & & & 0.09 & 0.17 \\
SMC-7 & & & & & & & & & & & $0.79^{* *}$ \\
\hline
\end{tabular}

Note: ${ }^{* *}(P<0.01),{ }^{*}(P<0.05) . C_{\mathrm{f}}$ : flow-weighted mean concentration driven by an event, flux: event-driven DOC quantity, $Q$ : total discharge volume, $R_{\mathrm{a}}$ : total rainfall amount, $R 1$ : total rainfall amount in the $1 \mathrm{~d}$ before the rainfall event, $R 7$ : total rainfall amount in the $7 \mathrm{~d}$ before the rainfall event, $R 14$ : total rainfall amount in the $14 \mathrm{~d}$ before the rainfall event, SMC-7 and SMC-14: soil moisture content in the 7 and $14 \mathrm{~d}$ before the rainfall event, $T_{\text {air }}-7$ and $T_{\text {air }}-14$ : mean air temperature in the 7 and $14 \mathrm{~d}$ before the rainfall event, REI: interval days between two rainfall events.
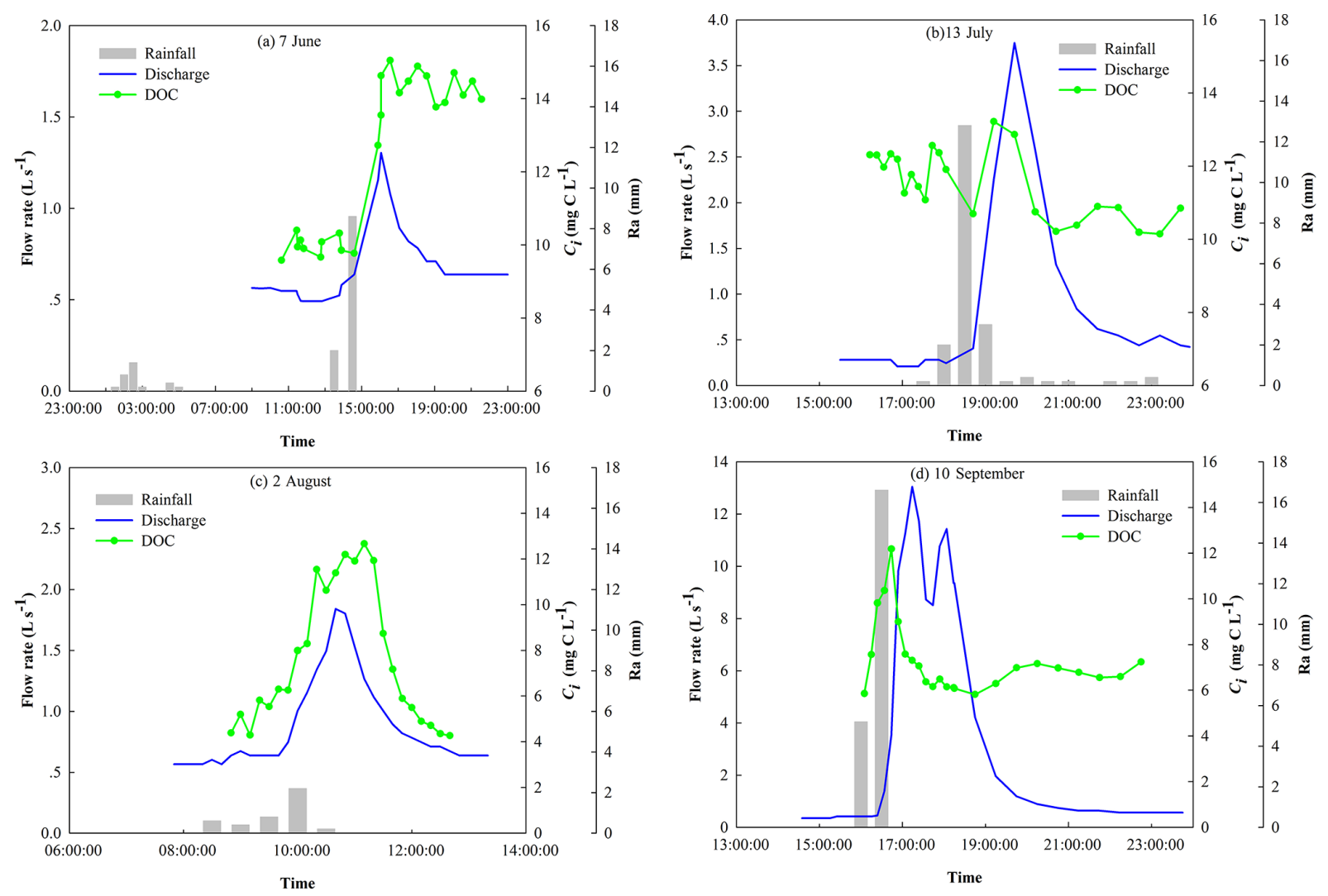

Figure 5. Dynamic changes of DOC concentration $\left(C_{i}\right)$ in an individual runoff event: (a) 7 June, (b) 13 July, (c) 2 August, (d) 10 September.

\subsection{DOC fluxes from catchment}

A rainfall event-based monitoring method is helpful to better understand the hydrological, DOC concentration and flux processes. The rainfall event-based DOC flux ranged from 0.18 to $2.84 \mathrm{~kg} \mathrm{~km}^{-2}$, with a mean DOC flux of $0.43 \mathrm{~kg} \mathrm{~km}^{-2}$ for all sampled rainfall events from June to September
2016. The relationship between event-based DOC flux and runoff discharge amount is shown in Fig. 4c. The DOC flux showed a positive linear relationship with the runoff discharge amount, especially for violent rainfall events. The DOC flux was more variable in lower runoff discharge conditions. In general, event-based DOC flux was significantly and positively correlated with $Q, R_{\mathrm{a}}, R 1$ and $R$, as shown 

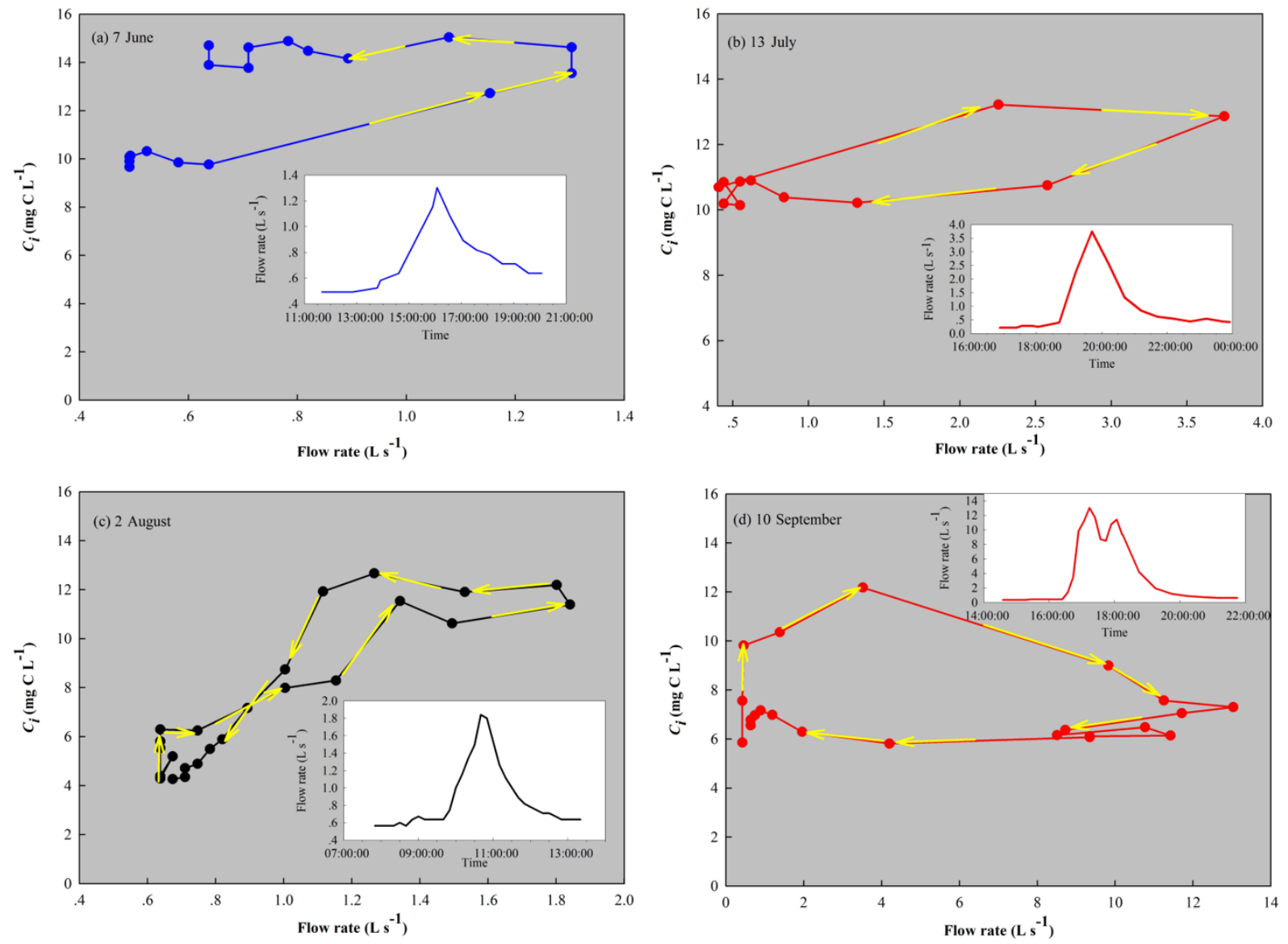

Figure 6. Hysteresis loops for four selected runoff events from June to September: (a) 7 June, (b) 13 July, (c) 2 August, (d) 10 September.

in Table 2. For the monthly DOC flux, the total DOC loading from the catchment ranged from $94.73 \mathrm{~kg} \mathrm{~km}^{-2}$ in August to $110.17 \mathrm{~kg} \mathrm{~km}^{-2}$ in September (Table 1). Although the total runoff discharge was lowest in June in these four months, the DOC monthly flux was $102.39 \mathrm{~kg} \mathrm{~km}^{-2}$ and had a higher flow-weighted DOC concentration $\left(11.52 \mathrm{mg} \mathrm{L}^{-1}\right)$. However, the DOC flux was higher in September, with an increased runoff discharge and a lower flow-weighted DOC concentration. The larger runoff discharge amount may offset the effects of lower DOC concentration.

\section{Discussion}

\subsection{Relationship between rainfall and DOC export}

It has been known that hydrological and carbon processes are important aspects of the regional carbon cycle and for restoring ecosystem services. However, the event-driven DOC exported from a catchment in the LRP has rarely been studied. In this study, we used an in situ auto- and high-frequency monitoring method to observe temporal changes in hydrological and DOC concentration for an event-based sampling period during the concentrated rainfall season (June-
September 2016) (Fig. 2b). For DOC export on a monthly scale, the DOC was calculated as the product of total discharge and flow-weighted mean concentration in a month, and thus these two variables represented hydrological and carbon biogeochemical processes. Monthly DOC fluxes were not clearly correlated with discharge amount. The flowweighted DOC concentrations decreased during the experimental period, which differed from the greater DOC flux with a large discharge (Chen et al., 2012; Cooper et al., 2007). Furthermore, the monthly DOC fluxes were negatively correlated with the discharge amount from June to $\mathrm{Au}-$ gust, 2016. The DOC concentration was higher in June and decreased in August. This was reasonable because the accumulated soil organic carbon can be flushed by runoff in early rainfall period, and the DOC concentration may be diluted by increased runoff (Blaen et al., 2017; Chen et al., 2012). In addition, in combination with the increased discharge amount, the decreased concentration led to a decrease in monthly DOC flux from June to August. This could be explained by the relative changes in DOC concentrations being higher than changes in monthly discharge, indicating that the decreased concentration may outweigh the effect of the increased discharge. However, the exception occurred in 


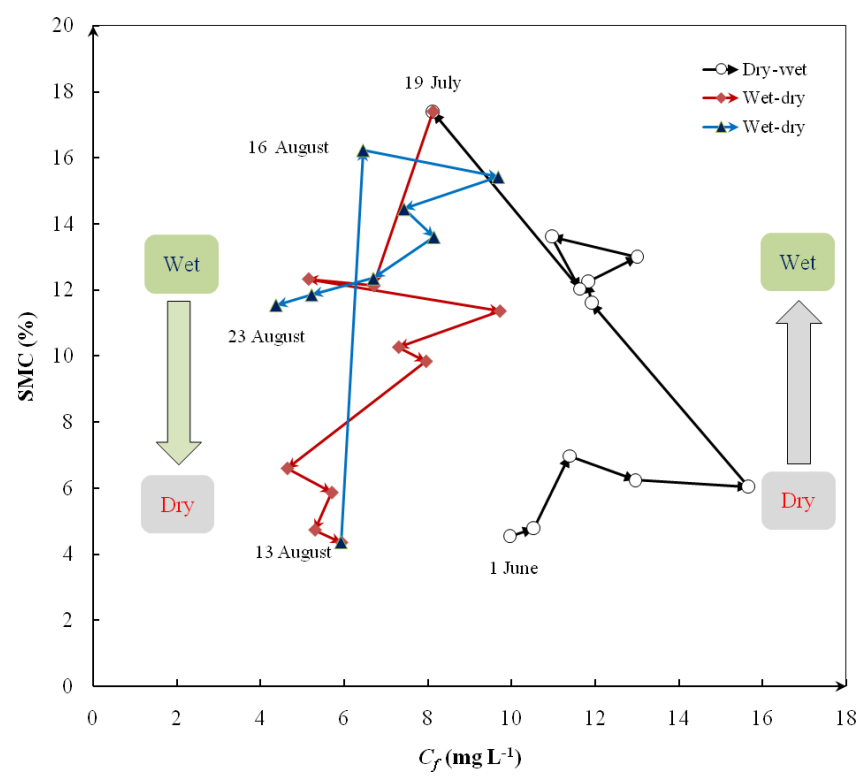

Figure 7. The changes of event-driven $C_{\mathrm{f}}$ (flow-weighted mean concentration) response to dry-wet and wet-dry variations in soil moisture content.

September, while increased DOC flux over the other three months was mainly due to a smaller increase in DOC concentration. These results were also probably associated with rainfall amount, land cover and runoff flow path (Laudon et al., 2004; Soulsby et al., 2003). For example, crops planted in the check-dam field were harvested, and the ratio of rainfall to runoff increased in September. The soil-soluble organic carbon is more likely to leach through macropores from check-dam farmland into runoff, which further increased the DOC concentration in runoff. Thus, it led to a slight increase in DOC flux in September. Therefore, it could be inferred from these results that DOC flux may depend on runoff flushing capacity and flow path in a restored and check-dam catchment.

Despite the fact that the DOC export varied in different months, there were also differences in DOC concentration and flux response to a rainfall event. DOC concentrations exhibited different dynamic changes throughout an eventdriven hydrological process. In our result, the anticlockwise hysteresis between DOC concentration and flow rate was observed on 7 June. The peak DOC concentration was delayed compared to the peak flow rate. These results may be attributed to a $5.2 \mathrm{~mm}$ rainfall happened earlier than the maximum rainfall at 7 June (Fig. 5a). The antecedent rainfall may increase connectivity in hydrology, and DOC sources may contribute to runoff. Thus, the dilution effect diminished as flow rate decreased and the increased connectivity lead to a relatively higher DOC concentration during the decreasing trend (Hope et al., 1994; Ma et al., 2018; Williams et al., 2017). A clockwise hysteresis was observed on 13 July and 10 September. The rapid response of the flow rate to rainfall can be attributed to the rainfall event with a shorter duration and larger rainfall amount. The higher discharge may bring a higher flushing capacity, thus an increased DOC concentration was observed during the increasing trend (Blaen et al., 2017; Tunaley et al., 2017). Moreover, the close link of DOC source to runoff may lead to a rapid increase in DOC concentration. A figure-of-eight hysteresis was observed on 2 August due to the DOC concentration keeping pace with the flow rate during the increasing and decreasing trends. Moreover, the event-driven DOC concentration on $2 \mathrm{Au}-$ gust showed no distinct difference with other three higher rainfall amount events. These results suggested that a lower discharge induced by lower rainfall amount have a more complex and larger influence on DOC concentration from a catchment in the LPR.

For event-driven flux, the DOC flux is a function of total runoff discharge and DOC concentration $\left(C_{\mathrm{f}}\right)$. DOC flux showed a positive linear relationship with runoff discharges, which is not surprising and parallel with studies reported by Clark et al. (2007) and Ma et al. (2018). In addition, it should be noted that the DOC flux induced by larger rainfall amounts was higher than flux driven by light rainfall, whereas the $C_{\mathrm{f}}$ showed no evident difference for the selected rainfall events. Thus, the greater DOC flux clearly showed that the DOC export was closely linked to hydrologic processes induced by various amount of rainfall events in the LPR. For an ecologically restored catchment in the LPR, the soil carbon driven by increased vegetation was significantly increased and acted as a positive pathway to the sequestration of soil carbon on terrestrial ecosystem (Wang et al., 2011b). Meanwhile, the reduced hydrology response to an increased vegetation may diminish soil carbon transported by hydrological processes in a catchment. The event-driven DOC transport is an important component for evaluating the carbon balance of the ecologically restored catchment in the LPR. Hence, further studies should include long-term undertakings to investigate the hydrological response and its impact on terrestrial carbon loss from a catchment in the LPR.

\subsection{Potential factors influence on DOC export}

The mechanisms of DOC export from terrestrial ecosystems may be complicated and depend on many factors, such as soil organic carbon, vegetation, rainfall, hydrological condition and sampling period (Blaen et al., 2017; Cooper et al., 2007; Ma et al., 2018). Comparatively few previous studies have investigated how changes in hydrological factors and rainfall affect DOC export. For instance, a rainfall event leads to changes in a hydrological process, and it may also simultaneously change soil moisture content, which may influence the soil carbon biogeochemical process. For the next rainfall event, the antecedent conditions, such as hydrological condition and the soil organic carbon content, may also influence the DOC concentration and flux. In general, antecedent conditions drive DOC export through exerting influence on the 
availability of DOC and impacts on hydrologic connectivity (Brocca et al., 2010; McMillan et al., 2018). Therefore, DOC export from a catchment during the rainfall event was the result of carbon biogeochemical processes, and the antecedent hydrological and rainfall characteristics.

The infrequency and amount of violent rainfall events strongly influence the runoff discharges and soil moisture, which in turn impact DOC during or after export from a catchment. In this study, temporal variations of rainfall, air temperature and soil moisture content were continuously monitored throughout the study period to provide detailed information describing the antecedent and current conditions. Positive correlation between $R_{\mathrm{a}}, R 7$ and $C_{\mathrm{f}}$ suggested that the combination of the rainfall amount and the accumulated rainfall before a rainfall event played important roles in DOC concentration for a rainfall event. $R 7$ may reflect the antecedent hydrological condition, and $R_{\mathrm{a}}$ represents the rainfall input into the catchment. Higher $R_{\mathrm{a}}$ and $R 7$ may lead to good hydrological connectivity, and thus more DOC sources may contribute to runoff. Therefore, $C_{\mathrm{f}}$ can by strongly influenced by $R_{\mathrm{a}}$ and $R 7$ due to the hydrological properties of the catchment. Apart from the hydrological changes, the antecedent soil moisture also played an important role in $C_{\mathrm{f}}$ and showed a significant and negative correlation with SMC7 and SMC-14 (Table 2). The soil moisture content was continuously dried and then effectively rewetted under a specific rainfall amount, as supported by the soil moisture variations shown in Fig. 2c. These results were also consistent with Yang et al. (2018), who found that the threshold of rainfall effectively recharged into soil was $20-26 \mathrm{~mm}$ for grassland and forest in the LPR. Therefore, the pattern of the soil moisture dry-wet cycle may affect event-driven DOC concentration, and this highlights the importance of soil moisture condition for DOC export (Fig. 7). The higher DOC concentrations from June to middle July coincided with light rainfall, and thus rainfall recharge into soil moisture. This is probably attributed to inactive microbial activity, caused by the relatively lower soil moisture (Jager et al., 2009). The DOC concentration decreased with increased soil moisture content, particularly on July 2018, with a total rainfall amount of $56.4 \mathrm{~mm}$. On the one hand, violent rainfall events may induce a higher discharge, causing a dilution effect on DOC concentration. On the other hand, the rainfall water may effectively replenish soil moisture content and thus stimulate a higher decomposition of soil carbon under wet and higher temperature condition. Then, the relative decreased DOC concentrations were observed under drying soil moisture conditions for the next rainfall events, which may attribute to an exhaustion of DOC (Laudon et al., 2004). These findings were similar to previous studies by Tunaley et al. (2017), who reported a strong influence of dry antecedent conditions on DOC export response to the rainfall event.

DOC flux was significantly and positively correlated with $Q, R_{\mathrm{a}}, R 1$ and $R 7$. The $Q$ and $R_{\mathrm{a}}$ reflect the direct effect of rainfall and hydrological processes during a rainfall event, while $R 1$ and $R 7$ refer to the antecedent rainfall conditions and reflect indirect effects on DOC export. These results agreed with previous studies demonstrated by Blaen et al. (2017), who noted that antecedent conditions and rainfall were key drivers of DOC export during a rainfall event. Cooper et al. (2007) also concluded that DOC export is largely governed by interactions between hydrological and meteorological factors and the carbon biogeochemical process. Overall, these results suggested that rainfall is a key factor influencing hydrological processes, and thus DOC export from an ecologically restored catchment in the LPR. Apart from the increased soil carbon driven by increased vegetation (Wang et al., 2011b), the weakened hydrological processes induced by increased vegetation may also cause a less terrestrial carbon export from a catchment. Therefore, our results highlight the need for research not only into the hydrological processes and soil carbon cycle, but also the integration of carbon export driven by a sequence of rainfall events across spatio-temporal scales to understand the carbon balance in a restored catchment in the LPR.

\section{Conclusion}

The DOC concentration and flux for individual rainfall events from a semi-arid catchment of the LPR was initially monitored during the concentrated rainfall season. DOC concentration showed a weak correlation with discharge, except in higher runoff discharge induced by extreme rainfall events. The findings of this study indicate that DOC concentrations were highly variable, particularly during low runoff discharge periods. Hysteresis analysis showed that the relationship between DOC concentration and runoff discharge for a rainfall event is nonlinear and varied with conditions in rainfall amount and the discharge process. DOC flux increased with runoff discharge and showed a positive linear correlation with runoff discharge. These results showed that higher DOC flux with low DOC concentration is related to higher discharge and its dilution effects in a hydrological process driven by larger rainfall amounts. The diluted DOC concentration induced by increased discharges contributed slightly to differences in DOC flux, due to total runoff discharge being a major variable for flux. These results showed that the temporal variation magnitude of DOC is related to hydrological conditions and antecedent conditions and suggested that the event-driven DOC export is largely influenced by rainfall through direct effects on catchment hydrology and indirect effects on soil carbon cycles. Changes in catchment hydrology and soil carbon processes and their responses to climate change may play an important role in terrestrial carbon export, particularly for a restored catchment. Thus, further work should focus on carbon export response to various rainfall events at a larger spatio-temporal scale, for better estimation of future terrestrial carbon in the aquatic ecosystem and evaluation of the carbon balance in ecologically restored 
catchments in the LPR. In addition, engineers and scientists can take advantage of the derived results to develop more advanced field monitoring work.

Data availability. The dataset used for this manuscript can be provided by e-mail contact with the first or corresponding author.

Author contributions. LW analysed data and organized the manuscript. HY discussed the relationship between DOC concentration or flux and runoff discharges induced by a sequence of rainfall events. XE carried out sampling and lab testing work. LC and YW discussed and guided the field monitoring work.

Competing interests. The authors declare that they have no conflict of interest.

Acknowledgements. We wish to thank Shibo Chen and Weiliang Chen for their help during the field sampling work and laboratory analysis.

Financial support. This work was financially supported by the National Nature Science Foundation of China (nos. 41671271, 41807176 and 41571130083 ).

Review statement. This paper was edited by Lixin Wang and reviewed by Guimin Liu and two anonymous referees.

\section{References}

Battin, T. J., Kaplan, L. A., Findlay, S., Hopkinson, C. S., Marti, E., Packman, A. I., Newbold, J. D., and Sabater, F.: Biophysical controls on organic carbon fluxes in fluvial networks, Nat. Geosci., 1, 95-100, 2008.

Bennett, E. M., Peterson, G. D., and Gordon, L. J.: Understanding relationships among multiple ecosystem services, Ecol. Lett., 12, 1394-1404, 2009.

Billett, M. F., Deacon, C. M., Palmer, S. M., Dawson, J. J. C., and Hope, D.: Connecting organic carbon in stream water and soils in a peatland catchment, J. Geophys. Res.-Biogeo., 111, G02010, https://doi.org/10.1029/2005JG000065, 2006.

Blaen, P. J., Khamis, K., Lloyd, C., Comer-Warner, S., Ciocca, F., Thomas, R. M., MacKenzie, A. R., and Krause, S.: Highfrequency monitoring of catchment nutrient exports reveals highly variable storm event responses and dynamic source zone activation, J. Geophys. Res.-Biogeo., 122, 2265-2281, 2017.

Brocca, L., Melone, F., Moramarco, T., Wagner, W., and Hasenauer, S.: ASCAT soil wetness index validation through in situ and modeled soil moisture data in central Italy, Remote Sens. Environ., 114, 2745-2755, 2010.
Chen, L., Huang, Z., Gong, J., Fu, B., and Huang, Y.: The effect of land cover/vegetation on soil water dynamic in the hilly area of the loess plateau, China, Catena, 70, 200-208, 2007.

Chen, N., Wu, J., and Hong, H.: Effect of storm events on riverine nitrogen dynamics in a subtropical watershed, southeastern China, Sci. Total Environ., 431, 357-365, 2012.

Clark, J. M., Lane, S. N., Chapman, P. J., and Adamson, J. K.: Export of dissolved organic carbon from an upland peatland during storm events: Implications for flux estimates, J. Hydrol., 347, 438-447, 2007.

Cooper, R., Thoss, V., and Watson, H.: Factors influencing the release of dissolved organic carbon and dissolved forms of nitrogen from a small upland headwater during autumn runoff events, Hydrol. Process., 21, 622-633, 2007.

Dawson, J., Billett, M., Neal, C., and Hill, S.: A comparison of particulate, dissolved and gaseous carbon in two contrasting upland streams in the UK, J. Hydrol., 257, 226-246, 2002.

Drake, T. W., Raymond, P. A., and Spencer, R. G. M.: Terrestrial carbon inputs to inland waters: A current synthesis of estimates and uncertainty, Limnology and Oceanography Letters, 3, 132142, 2018.

Evans, C. D., Monteith, D. T., Cooper, and D. M.: Long-term increases in surface water dissolved organic carbon: observations, possible causes and environmental impacts, Environ. Pollut., 137, 55-71, 2005.

$\mathrm{Fu}, \mathrm{B} .$, Zhao, W., Zhao, Q., and Liu, Y.: Changes of landscape pattern and soil erosion in Loess Plateau, Science Press, Beijing, 186-199, 2014 (in Chinese).

Fu, B., Wang, S., Liu, Y., Liu, J., Liang, W., and Miao, C.: Hydrogeomorphic ecosystem responses to natural and anthropogenic changes in the Loess Plateau of China, Annu. Rev. Earth Pl. Sc., 45, 223-243, 2017.

Hedge, J., Keil, R., and Benner, R.: What happens to terrestrial organic matter in the ocean?, Org. Geochem., 27, 195-212, 1997.

Hope, D., Billett, M., and Cresser, M.: A review of the export of carbon in river water: Fluxes and processes, Environ. Pollut., 84, 301-324, 1994.

Hu, B., Wang, P., Zhang, N., Wang, C., and Ao, Y.: Photoproduction of dissolved organic carbon and inorganic nutrients from resuspended lake sediments, Environ. Sci. Pollut. R., 23, 2212622135, 2016.

Inamdar, S. P., O’Leary, N., Mitchell, M. J., and Riley, J. T.: The impact of storm events on solute exports from a glaciated forested watershed in western New York, USA, Hydrol. Process., 20, 3423-3439, 2006.

Jager, D. F., Wilmking, M., and Kukkonen, J. V.: The influence of summer seasonal extremes on dissolved organic carbon export from a boreal peatland catchment: evidence from one dry and one wet growing season, Sci. Total Environ., 407, 1373-1382, 2009.

Kieber, R., Peake, B., Willey, J., and Avery, B.: Dissolved organic carbon and organic acids in coastal New Zealand rainwater, Atmos. Environ., 36, 3557-3563, 2002.

Laudon, H., Kohler, S., and Buffam, I.: Seasonal TOC export from seven boreal catchments in northern Sweden, Aquat. Sci., 66, 223-230, 2004.

Li, B. and Wang, L.: Statistical analysis of precipitation in recent 60 years in Yan'an, Shaanxi Water Resources, 1, 126-129, 2015 (in Chinese with English abstract). 
Liang, W., Bai, D., Jin, Z., You, Y., Li, J., and Yang, Y.: A Study on the Streamflow Change and its Relationship with Climate Change and Ecological Restoration Measures in a Sediment Concentrated Region in the Loess Plateau, China, Water Resour. Manag., 29, 4045-4060, 2015a.

Liang, W., Bai, D., Wang, F., Fu, B., Yan, J., Wang, S., Yang, Y., Long, D., and Feng, M.: Quantifying the impacts of climate change and ecological restoration on streamflow changes based on a Budyko hydrological model in China's Loess Plateau, Water Resour. Res., 51, 6500-6519, 2015b.

Lloyd, C. E., Freer, J. E., Johnes, P. J., and Collins, A. L.: Using hysteresis analysis of high-resolution water quality monitoring data, including uncertainty, to infer controls on nutrient and sediment transfer in catchments, Sci. Total Environ., 543, 388-404, 2016a.

Lloyd, C. E. M., Freer, J. E., Johnes, P. J., and Collins, A. L.: Technical Note: Testing an improved index for analysing storm discharge-concentration hysteresis, Hydrol. Earth Syst. Sci., 20, 625-632, https://doi.org/10.5194/hess-20-625-2016, $2016 \mathrm{~b}$.

Ma, X., Liu, G., Wu, X., Smoak, J. M., Ye, L., Xu, H., Zhao, L., and Ding, Y.: Influence of land cover on riverine dissolved organic carbon concentrations and export in the Three Rivers Headwater Region of the Qinghai-Tibetan Plateau, Sci. Total Environ., 630, 314-322, 2018

McMillan, S., Wilson, H., Tague, C., Hanes, D., Inamdar, S., Karwan, D., Loecke, T., Morrison, J., Murphy, S., and Vidon, P.: Before the storm: antecedent conditions as regulators of hydrologic and biogeochemical response to extreme climate events, Biogeochemistry, 141, 487-501, 2018.

Mulholland, P.: Large-Scale Patterns in Dissolved Organic Carbon Concentration, Flux, and Sources. in Aquatic Ecosystems Interactivity of Dissolved Organic Matter, edited by: Findlay, S. E. G. and Sinsabaugh, R. L., Academic, San Diego, 139-159, 2003.

Ran, L., Tian, M., Fang, N., Wang, S., Lu, X., Yang, X., and Cho, F.: Riverine carbon export in the arid to semiarid Wuding River catchment on the Chinese Loess Plateau, Biogeosciences, 15, 3857-3871, https://doi.org/10.5194/bg-15-3857-2018, 2018.

Raymond, P. A. and Saiers, J. E.: Event controlled DOC export from forested watersheds, Biogeochemistry, 100, 197-209, 2010.

Raymond, P. A., Hartmann, J., Lauerwald, R., Sobek, S., McDonald, C., Hoover, M., Butman, D., Striegl, R., Mayorga, E., Humborg, C., Kortelainen, P., Durr, H., Meybeck, M., Ciais, P., and Guth, P.: Global carbon dioxide emissions from inland waters, Nature, 503, 355-359, 2013.
Ritson, J. P., Graham, N. J., Templeton, M. R., Clark, J. M., Gough, R., and Freeman, C.: The impact of climate change on the treatability of dissolved organic matter (DOM) in upland water supplies: a UK perspective, Sci. Total Environ., 473-474, 714-730, 2014.

Shi, H. and Shao, M.: Soil and water loss from the Loess Plateau in China, J. Arid Environ., 45, 9-20, 2000.

Soulsby, C., Rodgers, P., Smart, R., Dawson, J., and Dunn, S.: A tracer-based assessment of hydrological pathways at different spatial scales in a mesoscale Scottish catchment, Hydrol. Process., 17, 759-777, 2003.

Systat, Sigma Plot, Version 10.0, Systat Software Inc., San Jose, CA, 2008.

Tang, K.: Soil and water conservation in China, Chinese Science Press, Beijing, 15-20, 2004 (in Chinese).

Tunaley, C., Tetzlaff, D., and Soulsby, C.: Scaling effects of riparian peatlands on stable isotopes in runoff and DOC mobilisation, J. Hydrol., 549, 220-235, 2017.

Wang, Y., Fu, B., Chen, L., Lu, Y., and Gao, Y.: Check dam in the Loess Plateau of China: engineering for environmental services and food security, Environ. Sci. Technol., 45, 10298-10299, 2011a.

Wang, Y., Fu, B., Lü, Y., and Chen, L.: Effects of vegetation restoration on soil organic carbon sequestration at multiple scales in semi-arid Loess Plateau, China, Catena 85, 58-66, 2011 b.

Wang, Y., Chen, L., Gao, Y., Chen, S., Chen, W., Hao, Z., Jia, J., and Han, N.: Geochemical isotopic composition in the Loess Plateau and corresponding source analyses: A case study of China's Yangjuangou catchment, Sci. Total Environ., 581-582, 794-800, 2017.

Wei, W., Jia, F., Yang, L., Chen, L., Zhang, H., and Yu, Y.: Effects of surficial condition and rainfall intensity on runoff in a loess hilly area, China, J. Hydrol., 513, 115-126, 2014.

Willey, J., Kieber, R., Eyman, M., and Avery, G. B.: Rainwater dissolved organic carbon: concentrations and global flux, Global Biogeochem. Cy., 14, 139-148, 2000.

Williams, M., King, K., and Fausey, N.: Dissolved organic carbon loading from the field to watershed scale in tile-drained landscape, Agr. Water Manage., 192, 159-169, 2017.

Yang, L., Zhang, H., and Chen, L.: Identification on threshold and efficiency of rainfall replenishment to soil water in semi-arid loess hilly areas, Science China Earth Sciences, 61, 292-301, 2018. 